\title{
A PROBLEMÁTICA DA TUTELA JURÍDICA DOS REFUGIADOS AMBIENTAIS NO BRASIL: Análise da Concessão do Visto Humanitário Concedido Pelo Conselho Nacional de Imigração
}

\section{Tiago Baptistela}

\begin{abstract}
Mestrado em Direito pela Universidade Federal de Santa Maria (UFSM). Pós-Graduação Lato Sensu em Direito Civil pela Universidade do Sul de Santa Catarina (Unisul). Pós-Graduação Lato Sensu em Direito de Família e Sucessões pela Universidade Anhanguera (Uniderp). Graduação em Direito pelo Centro Universitário Franciscano (Unifra). Notário e registrador substituto. Associado no Instituto Brasileiro de Direito de Família (IBDFAM). Experiência na área de Direito, atuando principalmente nos seguintes temas: Direito Civil (Contratos, Família e Sucessões), Direito Constitucional, Direito Internacional, Direito Imobiliário, Direito Notarial e Registral e Mediação de Conflitos. tiagobaptistela.direito@gmail.com
\end{abstract}

\section{Resumo:}

0 presente estudo tem por objetivo analisar as repercussões jurídicas do tratamento destinado aos deslocados internacionais ambientais cujo tema vem ocupando maior espaço nas discussões acadêmicas, contudo ainda não é traduzido expressamente em documentos jurídicos internacionais. No Brasil, a Resolução n. 97/2012 do Conselho Nacional de Imigração, alterada pela Resolução n. 102/2013, é o primeiro documento normativo brasileiro que enfrenta a questão dos deslocamentos ambientais, ao regular 0 visto humanitário aos haitianos, tendo como causa o terremoto ocorrido naquele país em janeiro de 2010 . A pesquisa parte de uma abordagem dedutiva, uma vez que analisa a possibilidade de ampliação do conceito de refugiado, bem como utiliza uma técnica de pesquisa descritiva, a partir das normativas internacionais acerca do tema. Os atuais instrumentos internacionais de proteção aos refugiados, como a Convenção de Genebra sobre Refugiados de 1951 e o Protocolo de 1967, trazem o conceito tradicional de refúgio. A definição foi ampliada pela Declaração de Cartagena de 1984, que considera refugiados pessoas que tenham fugido dos seus países porque sua vida, segurança ou liberdade encontra-se ameaçada pela violência generalizada, a agressão estrangeira, os conflitos internos e a violação maciça dos direitos. A Lei 9.474/97, inspirada na Declaração de Cartagena, ampliou o conceito tradicional de refugiado para a vítima da violação grave e generalizada de direitos humanos. 0 Comitê Nacional para os Refugiados (Conare), contudo, ao recusar a solicitação de refúgio a haitianos após o terremoto de 2010, remeteu ao Conselho Nacional de Imigração o compromisso de regular a condição jurídica desse imigrante no Brasil. Assim, instituiu-se pela Resolução n. 97/2012 do Conselho Nacional de Imigração (CNIg), cujo visto humanitário, a partir da competência estabelecida pela Resolução Normativa n. 27, de 25 de novembro de 1998, que disciplina a avaliação de situações especiais e casos omissos pelo CNIg. Ao avaliar a concessão do visto humanitário atribuído aos haitianos, com base na Resolução Normativa n. 97/2012, 0 
Estado brasileiro, por meio do CNIg, agiu de forma provisória, arbitrária e discricionária, ao interpretar de forma restrita a aplicação da concessão de refúgio disposto na Lei no 9.474/97, expondo os imigrantes ambientais à vulnerabilidade e violação dos direitos humanos.

\section{Palavras-chave:}

Refugiados ambientais. Visto humanitário. Conselho Nacional de Imigração.

\section{THE PROBLEM OF THE LEGAL TREATMENT OF ENVIRONMENTAL REFUGEES IN BRAZIL: ANALYSIS OF THE GRANTING OF THE HUMANITARIAN VISA GRANTED BY THE NATIONAL IMMIGRATION COUNCIL}

\section{Abstract}

This study aims to examine the legal implications of treatment as international environmental displaced whose theme is taking more space in academic discussions, but is not explicitly translated into international legal documents. In Brazil, Resolution n. 97/2012 of the National Immigration Council, as amended by Resolution no. 102/2013, is the first Brazilian normative document that addresses the question of environmental shifts, the regular humanitarian visas to Haitians, caused by the earthquake of January 2010 The research part of a deductive approach, since it examines the possibility expansion of the concept of refugee, and uses a technique of descriptive research from the international standards on the subject. The current international instruments for the protection of refugees and the Geneva Convention on Refugees 1951 and Protocol of 1967, bringing the traditional concept of refuge. The definition was expanded by the 1984 Cartagena Declaration, considered refugees, who have fled their country because their lives, safety or freedom is threatened by generalized violence, foreign aggression, internal conflicts, massive violation of rights. Law 9.474/97, inspired by the Declaration of Cartagena, expanded the concept of refugee traditional for the victim of serious and widespread human rights violations. However, Conare to refuse the request for refuge to Haitians after the earthquake of 2010, referred to the National Immigration Council's commitment to regulate the legal status of this immigrant in Brazil. Thus, it was created by resolution. 97/2012 of CNIg whose humanitarian visa from the competence established by Resolution $\mathrm{n}$. 27 of 25 November 1998, which governs the assessment of special situations and Omissions by CNIg. When evaluating the granting of humanitarian visa granted to Haitians, based on Normative n. 97/2012, the Brazilian government through CNIg acted provisional arbitrary and discretionary, so to interpret narrowly the application of design of refuge provision in Law no 9.474 / 97, exposing the vulnerability and environmental migrants human rights violation.

\section{Keywords:}

Environmental Refugees. Humanitarian visa. National Migration Board.

Recebido em: 5/1/2017

Aceito em: 1\%/6/2018

\section{Sumário:}

1 Introdução. 2 A Problemática da Tutela Jurídica dos Refugiados Ambientais no Brasil. 2.1 A Crise Ambiental Como Causa da Migração. 2.2 As Migrações Internacionais. 2.3 A Insuficiência do Direito Internacional no Amparo aos Refugiados Ambientais. 2.4 A Dimensão Social, Econômica e Ambiental. 3 A Superação da Problemática da Tutela Jurídica do Refugiado Ambiental no Brasil: o caso haitiano. 3.1 Análise da Concessão do Visto Humanitário Concedido pelo Conselho Nacional de Refúgio. 3.2 A Concessão do Visto Humanitário Versus Status de Refúgio. 4 Considerações Finais. 5 Referências. 


\section{INTRODUÇÃO}

A intensificação do fluxo mundial de refugiados ambientais está relacionada com a interferência de desastres ambientais, mudanças climáticas, uso indiscriminado de compostos químicos danosos à natureza que, consequentemente, acabam por dificultar ou impossibilitar a própria permanência humana em determinados locais do planeta.

Dessa forma, a crescente escassez de recursos naturais e a intensificação dos eventos climáticos extremos têm provocado situaçôes as mais diversas sobre a sociedade e a natureza, incluindo a migraçáo em massa de pessoas que, muitas vezes, se deslocam para fora do seu país de origem em busca de proteção.

Nesse sentido, o tema dos refugiados ambientais impóe grandes desafios à sociedade, à política, à economia e ao Direito, pois os movimentos migratórios têm aumentado num período em que muitos países do mundo mantêm as políticas de restrição migratória em seu espaço geográfico.

Por isso, a crise climática global associada à crise migratória internacional pode tornar-se uma preocupação de segurança internacional devido ao aumento dos conflitos internacionais, e tem como efeito direto a violaçáo dos direitos humanos já consagrados em normas de Direito Interno e Internacional.

Verifica-se que atualmente inexiste proteção jurídica específica para o migrante ambiental, bem como não há norma ou costume internacional consagrado de recepção de refugiados ambientais com base em assistência humanitária ou em um dever de solidariedade internacional.

Os atuais instrumentos internacionais de proteção aos refugiados, como a Convenção de Genebra sobre Refugiados de 1951 e o Protocolo de 1967, trazem o conceito tradicional de refúgio.

No Brasil, a Lei 9.474/97, inspirada na Declaração de Cartagena, ampliou o conceito tradicional de refugiado para a vítima de violação grave e generalizada de direitos humanos.

Nesse contexto, avaliar a concessão do visto humanitário concedido aos haitianos, com base na Resolução Normativa n. 97/2012, é a proposta que passamos a analisar. 


\section{A PROBLEMÁTICA DA TUTELA JURÍDICA DOS REFUGIADOS AMBIENTAIS NO BRASIL}

\subsection{A Crise Ambiental Como Causa da Migração}

As crises e desastres ambientais deflagraram uma nova ordem de problemática internacional, pois esses eventos de proporçôes catastróficas são creditados à interferência da ação humana no meio ambiente como suas principais causas e consequências.

Observa-se que antigamente essas catástrofes eram atribuídas a causas provenientes da intervençáo divina na Terra, e que hoje a realidade nos condiciona a verificarmos a interferência humana como causa desse ambiente hostil, resultado do aquecimento global, poluição atmosférica e dos rios, desmatamento, entre outros.

Nesse sentido, encontramos os refugiados relacionados a problemas ambientais, resultante do problema causado pela relação "homem e natureza", que expulsa os seres humanos de seu mundo (BARROS, 2011).

Dessa forma, uma nova concepção jurídica em atenção a essa categoria de refugiados ocorre diante da realidade de pessoas que viviam no seu país de origem, diante da ocorrência de profundas mudanças climáticas e ambientais, que motiva a intenção de migrar definitivamente para outro país e torna a volta quase impossível.

Verifica-se, portanto, a existência de um novo ator global, o refugiado ambiental, que diante de um processo de vulnerabilidade do meio ambiente no seu país de origem movimenta-se fugindo dos desastres e crises ambientais, preocupando a ordem internacional sobre quais serão as consequências num futuro próximo.

\subsection{As Migrações Internacionais}

A crescente escassez de recursos naturais e a intensificação de eventos climáticos extremos têm provocado situaçóes as mais diversas sobre a sociedade e a natureza, incluindo a migração em massa de pessoas que, muitas vezes, se deslocam para fora do seu país de origem em busca de proteção. 
A intensificação do fluxo mundial da mobilidade humana está relacionada com a interferência de desastres ambientais, mudanças climáticas, uso indiscriminado de compostos químicos danosos à natureza que, consequentemente, acabam por dificultar ou impossibilitar a própria permanência humana em determinados locais do planeta.

Além de acontecimentos repentinos como tsunamis, terremotos, furacôes, inundaçôes, cuja magnitude e efeitos são de fácil visualização, observa-se que a exploração, escassez e contaminação de recursos ambientais, de forma contínua e progressiva (e menos visível no curto prazo) também podem comprometer gravemente a vida humana e a biodiversidade em diversas regiôes, tornando-as improdutivas, inabitáveis e, no longo prazo, impróprias para sobrevivência. Da mesma forma, a instalação e/ou gestão inadequada de empreendimentos potencialmente degradadores do meio ambiente podem gerar impactos negativos com efeitos irreversíveis.

Dessa forma, os migrantes que são obrigados a saírem do local onde vivem para outros países em virtude da interferência de eventos ambientais catastróficos, ou causadores de profundas mudanças naquele ambiente, caracterizam-se como migrantes ambientais.

Conforme definição apresentada pelo Instituto de Migraçôes e Direitos Humanos (2016), migrante é "toda pessoa que se transfere de seu lugar habitual, de sua residência comum para outro lugar, região ou país".

Já o conceito dos migrantes ambientais havia sido inicialmente popularizado como "refugiados ecológicos" por Lester Brown, em 1976, do Worldwatch Institute, com a primeira definição deste fenômeno sendo proposta por El-Hinnawi, em 1985, em um relatório desenvolvido para a Programa das Naçóes Unidas para o Meio Ambiente (Pnuma), no qual os "refugiados ambientais" (expressão usada no relatório) são definidos como sendo aquelas pessoas que foram forçadas a deixar suas casas, temporária ou permanentemente, por causa de uma evidente alteração ambiental (natural e/ou desencadeada por atividade humana) que comprometeu sua existência e/ou afetou seriamente a qualidade de suas vidas (BARROS, 2011).

No ano de 1988 o Pnuma (2016) deu ênfase a um conceito próprio de refugiados ambientais, definindo-os como 
pessoas obrigadas a abandonar temporária ou definitivamente a zona onde tradicionalmente viviam, devido ao visível declínio do ambiente, perturbando a sua existência e/ou a qualidade da mesma de tal maneira que a subsistência dessas pessoas entrasse em perigo.

A variável de migrantes e refugiados ambientais na definição de um conceito razoável poder explicativo dificulta o desenvolvimento de estudos qualitativos mais aprofundados que possam contribuir para o desenvolvimento de respostas jurídicas e políticas que efetivamente atendam às necessidades dos migrantes ambientais.

Os conceitos, entretanto, não refletem uma realidade jurídica, pois a Organização das Naçóes Unidas foi uma das instituiçóes pioneiras na busca de atenção aos refugiados desde sua criação (1946) e na Declaração Universal dos Direitos Humanos (1948), pois após o período das grandes guerras mundiais emergiu a necessidade do reconhecimento internacional sobre a intenção de promover a paz e a defesa dos direitos humanos, bem como a criação de mecanismos jurídicos de proteção dos direitos das pessoas em situação de perseguição em seus países de origem.

Nesse ambiente surge o instituto jurídico do "refúgio" disciplinado na $4^{\mathrm{a}}$ Convenção de Genebra, ${ }^{1}$ com o objetivo de proteção às pessoas civis em tempos de guerra, na data de 12 agosto de 1949, que disciplinou o tema, mas que foi oficializado com a aprovação da Convenção das Naçóes Unidas sobre o Estatuto dos Refugiados em 1951.

Durante essa época a Assembleia Geral da Organização das Naçóes Unidas (ONU) criou em 1950 o Alto-Comissário das Naçôes Unidas para os Refugiados (Acnur), com a incumbência de trabalhar de forma apolítica, humanitária e social,

\footnotetext{
${ }^{1}$ As Convençôes de Genebra são uma série de tratados formulados em Genebra, na Suíça, definindo as normas para as leis internacionais relativas ao Direito Humanitário Internacional. As convençôes foram o resultado de esforços de Henri Dunant, que foi motivado pelos horrores de que foi testemunha na Batalha de Solferino. Esses tratados definem os direitos e os deveres de pessoas, combatentes ou não, em tempo de guerra. Tais tratados são inéditos, consistindo na base dos direitos humanitários internacionais. Os tratados foram elaborados durante quatro Convençóes de Genebra que aconteceram de 1864 a 1949. Disponível em: http://pt.wikipedia.org/wiki/Conven\%C3\%A7\%C3\%B5es_de_Genebra. Acesso em: 10 out. 2016.
} 
tendo como principais incumbências providenciar a proteção internacional e buscar soluçôes permanentes para o problema dos refugiados, desenvolvendo um trabalho profundamente humanitário.

A definiçáo de refugiado, no entanto, estava atrelada, predominantemente, a aspectos de raça, conflitos bélicos, religiosos, culturais, ideológicos, como se verifica na alínea c do $\$ 1^{\circ}$ do Artigo $1^{\circ}$, que o refugiado significa a pessoa

perseguida por motivos de raça, religião, nacionalidade, grupo social ou opinióes políticas, se encontra fora do país de sua nacionalidade e que não pode ou, em virtude desse temor, não quer valer-se da proteção desse país, ou que, se não tem nacionalidade e se encontra fora do país no qual tinha sua residência habitual em conseqüência de tais acontecimentos, não pode ou, devido ao referido temor, não quer voltar a ele.

Dessa forma, o questionamento a respeito do conceito clássico de refugiado tem trazido para a discussão outras formas de discriminação, bem como de sofrimentos decorrentes de situaçôes até então ausentes ou ainda muito pouco evidentes.

Nesse sentido, para a Organização Internacional para Migração (OIM, 2016), os "migrantes ambientais" são pessoas ou grupos de pessoas que, por razões imperiosas de mudanças repentinas ou progressivas no ambiente que afetam negativamente sua vida ou suas condições de vida, são obrigadas a deixar suas casas, ou optam por deixá-las temporária ou permanentemente, e que se deslocam internamente ou para outros países.

No ano de 1967 foi criado, então, o Protocolo sobre o Estatuto dos Refugiados, com a finalidade de resolver os problemas gerados pelas duas limitaçóes (temporal e geográfica) da Convenção. Colocava-se fim à reserva temporal, ao mesmo tempo que se exigia que os Estados que se comprometessem com as obrigaçôes da Convenção ao aderir ao Protocolo não adotassem mais a reserva geográfica.

Na América Latina a Declaração de Cartagena é um marco na conceituação de refugiado. Resultado de um acordo entre países da América Central, foi emanada em 1984, considerando a violência generalizada, invasão estrangeira e conflitos internos como razóes que justificam o pedido e a concessão de refúgio. 
No Estado brasileiro foi promulgada em 22 de julho de 1997 a Lei ${ }^{\circ}$ 9.474/97, tratando sobre os direitos dos refugiados e suas diretrizes, instituída pela Convenção da ONU sobre o Estatuto dos Refugiados (1951).

Assim, foi criado o Comitê Nacional para os Refugiados (Conare), ligado ao Ministério da Justiça e com composição multidisciplinar, que possui competência para processar e decidir os pedidos de obtenção do status de refúgio no Brasil.

Observa-se, entretanto, que a temática dos refugiados ambientais - objeto de análise do presente artigo - não possui suporte jurídico no Direito Internacional e Nacional do ponto de vista legal.

Trata-se, portanto, de novo ator global que surgiu associado a atividades como as emissóes de gases do efeito estufa, desmatamentos e demais agressóes ao meio ambiente, com as mudanças climáticas responsáveis pelo derretimento de geleiras, inundaçóes, secas, aumento do nível dos oceanos e demais impactos ambientais.

\subsection{A Insuficiência do Direito Internacional no Amparo aos Refugiados Ambientais}

Os atuais instrumentos internacionais de proteção aos refugiados, quer seja no âmbito global, como a Convenção de Genebra sobre refugiados, ou regional, como a Declaração de Cartagena e a lei 9.474/97, apresentam-se insuficientes para proteger as pessoas que se deslocam por razóes ambientais, pelo fato de, ou se referirem a uma categoria específica de pessoas deslocadas, como os refugiados perseguidos por causas políticas, religiosas, raciais ou sociais, ou estarem limitados geograficamente ou, ainda, por não realizarem qualquer menção às pessoas que se movimentam internamente no território de seus próprios países.

Os conceitos, princípios e mecanismos jurídicos e políticos expressos por tais instrumentos, entendidos como as principais fontes do Direito Internacional dos refugiados, mostram-se inadequados para tratar de um número bem maior de pessoas forçadas a se deslocarem pelo planeta, por razóes que não sejam as previstas nos institutos normativos. 
A manifestação não significa que, no contexto de seus propósitos eles não sejam importantes e eficientes, contudo suas limitaçôes impedem a proteçấo a todos aqueles que realmente precisam.

O Direito Internacional dos refugiados é, dessa maneira, no mínimo insuficiente, para tratar dos deslocados ambientais, havendo a necessidade de se efetivar, desde o reconhecimento formal de tais grupos, até a formatação de um novo acordo, independente ou concebido a partir da modificaçáo dos documentos já existentes em âmbito internacional, que estabeleça direitos a estas pessoas, que atribua responsabilidades aos países que deram causa aos deslocamentos e que crie mecanismos de mitigação de suas consequências.

O Direito Ambiental Internacional, por sua vez, tem evoluído nos últimos anos com a formatação de inúmeros instrumentos globais de proteção aos recursos naturais, a partir das questôes que vão sendo construídas e colocadas à prova.

Originam-se desta preocupação os acordos internacionais de proteção à biodiversidade (solos, florestas, mar, clima, atmosfera, fauna, etc.). além da regulamentação de atividades perigosas.

Conforme Cournil e Mazzega (2007), esta área do Direito desenvolveu-se mais no sentido de elaborar mecanismos de responsabilidade e compensação sem, contudo, ater-se aos aspectos de assistência e gestáo às crises ambientais que garantam a proteção imediata à vida.

Nesse aspecto, ao defender que sejam criadas ferramentas de atribuição de responsabilidades e de mitigação, objetiva-se que estas não se deem somente como forma de compensação dos danos, mas que procurem garantir o direito a um meio ambiente ecologicamente equilibrado, fundamental à manutençáo da vida humana e de todos os seres vivos.

Antônio Augusto Cançado Trindade (1993), por sua vez, manifesta-se sabiamente: 
O caráter fundamental do direito à vida torna inadequados enfoques restritos do mesmo em nossos dias; sob o direito à vida, em seu sentido próprio e moderno, não só se mantém a proteção contra qualquer privação arbitrária da vida, mas além disso encontram-se os Estados no dever de "buscar diretrizes destinadas a assegurar o acesso aos meios de sobrevivência”.

A própria ajuda humanitária oferecida no caso de desastres ambientais, e que prevê a entrada de organismos de assistência às vítimas nos territórios dos países, depende de um posicionamento do Estado atingido em permitir tal acesso, o que torna esse mecanismo, mesmo que desenvolvido no âmbito das Naçóes Unidas, precário para, efetivamente, proteger a vida das pessoas atingidas por catástrofes ambientais.

O Acnur, atualmente responsável, no âmbito das Naçóes Unidas, pela proteção dos refugiados segundo a Convenção de Genebra de 1951, teria de sofrer modificaçóes que lhe permitissem ampliar suas articulaçóes com os Estados, no caso da inclusão da categoria das pessoas deslocadas no texto da própria convenção.

Destaca-se que o reconhecimento jurídico dos refugiados ambientais tem enfrentado resistência nos âmbitos político e jurídico internacionais, principalmente porque os Estados que são ou seráo receptores desses contingentes humanos não querem ou não podem assumir responsabilidades além daquelas já desenvolvidas em relação aos demais imigrantes presentes em seu território.

Ressalta-se que o Direito interno dos Estados, por meio de suas normas e dos tratados internacionais de que faz parte, devem ser aplicáveis aos refugiados ambientais naquilo que lhes cabe, pois estes fazem jus a todos os direitos garantidos à pessoa humana.

Ocorre que dentro do seu próprio território os Estados têm obrigação legal de proteger quaisquer pessoas que se encontrem nos limites de sua jurisdição, sejam eles nacionais ou estrangeiros.

No caso dos deslocados, sejam eles motivados por causas ambientais ou não, a obrigação legal de proteção estatal se mantém, mesmo que na prática o governo nacional esteja impossibilitado de fazê-lo, como no caso de guerras ou de o Estado ser considerado falido. 
Salienta-se que o Direito Internacional dos direitos humanos não prevê explicitamente uma proteção jurídica direcionada a vítimas de desastres, mas tanto a proteção quanto o auxílio a essas pessoas estão implícitos na normativa internacional de direitos humanos.

Assim, o principal motivo pelo qual os refugiados ambientais merecem não apenas uma proteção baseada em instrumentos jurídicos já existentes, mas, sobretudo, em normas internacionais que sejam direcionadas para atacar as privaçóes derivadas da sua condição específica, deve-se ao fato de que esses migrantes possuem fragilidades particulares decorrentes da própria condição socioambiental que os obrigou a migrar.

Embora a alteração da Convenção da ONU sobre o Estatuto dos Refugiados em 1967 tenha mantido numerus clausus a proteção dos refugiados, o número de pessoas que se encontram em situaçóes político-jurídicas análogas às dos refugiados aumentou.

O refugiado ambiental, portanto, objeto da presente análise, não é considerado um refugiado nos termos da Convenção de 1951 e do seu Protocolo de 1967, uma vez que tais normas jurídico-internacionais não estabelecem a proteção de refugiado àquelas pessoas que migraram forçadamente em razão de danos e catástrofes ambientais.

Independentemente da solução adotada, contudo, tem-se a certeza de que os pressupostos jurídicos de proteçáo à vida dos deslocados ambientais e todas as outras garantias que dela decorrerem precisam ser positivados, do mesmo modo que a formatação de sistemas internacionais que estabeleçam mecanismos de mitigação dos resultados e compensaçáo dos danos decorrentes dos eventos que causam a origem desses grupos.

\subsection{A Dimensão Social, Econômica e Ambiental}

Entre as inúmeras dimensões a serem consideradas em um contexto de drásticas mudanças do ambiente natural, encontra-se a dimensão humana, uma vez que os deslocamentos populacionais forçados, motivados por causas 
ambientais, demandam uma atenção não menos cuidadosa que o aspecto econômico, político e sociocultural da degradação ambiental global (EL-HINNAWI, 1985). ${ }^{2}$

Aparentemente essas perspectivas parecem não dialogar, pois de um lado está a perspectiva humanitária, de assistência aos deslocados e aos refugiados. De outro, as demais perspectivas: ambiental, econômica, política. Ambas, todavia, estão relacionadas ao fenômeno das alteraçóes do ambiente global e não só podem, mas devem se comunicar. A inter-relação necessária entre as diversas perspectivas será sempre ressaltada ao longo do presente texto.

Após a demonstração da sua complexidade e das inúmeras dimensóes que o tema compreende nos planos ambiental, econômico, político, social e humanitário e que devem estar necessariamente conectados, assim como a inviabilidade de tratá-los de forma compartimentada, restam claros os fundamentos para a construção de um tratamento inovador a partir do reconhecimento de uma nova categoria de refugiados.

Em 1995, o cientista ambiental Norman Myers, vislumbrando um cenário alarmante de "êxodos ambientais" que se agravaria significativamente no futuro, destaca os impactos do aquecimento global nesse processo (aumento do nível do mar e inundaçóes nas áreas costeiras), sem deixar de considerar outros fatores que, segundo ele, exacerbam os problemas ambientais.

Myers ressalta a importância de uma definição que seja facilmente compreendida, passível de demonstração (documentação e quantificação) para tomadores de decisão, gestores e cientistas. Assim, propôs a seguinte definição, visando a separar os migrantes econômicos dos "refugiados ambientais":

2 Para Essam El-Hinnawi, a quem se atribui a popularização da expressão "refugiados ambientais", a conexão entre as múltiplas dimensōes do problema seria inerente, uma vez que as categorias de refugiados ambientais criam uma série de problemas ambientais, socioeconômicos e culturais que, por sua vez, afetam o ambiente físico natural das áreas para as quais os refugiados se dirigem e a qualidade de vida dos próprios refugiados e dos habitantes das áreas para as quais eles migram. 
Refugiados ambientais são pessoas que já não conseguem ter uma vida segura em sua terra natal por causa de fatores ambientais de âmbito incomum. Esses fatores incluem a seca, a desertificação, desmatamentos, erosão do solo e outras formas de degradação dos solos; déficits de recursos, tais como a escassez de água, o declínio dos habitats urbanos através da sobrecarga maciça dos sistemas de cidade, problemas emergentes, tais como as mudanças climáticas, especialmente o aquecimento global, e desastres naturais como ciclones, tempestades e inundações, terremotos, com impactos agravados pela má gestão humana. Pode haver fatores adicionais que exacerbam os problemas ambientais e que muitas vezes resultam, em parte, de problemas ambientais: o crescimento populacional, pobreza generalizada, fome e doença pandêmica. Ainda há outros fatores que incluem as políticas de desenvolvimento deficiente e sistemas de governo que marginalizam o povo em sentido econômico, político, social e jurídico. Em determinadas circunstâncias, um número de fatores pode servir de "gatilhos" imediatos da migração, por exemplo, grandes acidentes industriais e construção de grandes barragens. Desses fatores múltiplos, vários podem operar em conjunto, muitas vezes com impactos agravados. Diante dos problemas ambientais, pessoas envolvidas sentem que não têm alternativa senão a de buscar o sustento em outro lugar, dentro dos seus países ou em outros países, numa base semipermanente ou permanente. ${ }^{3}$

Dessa forma, o conceito anteriormente mencionado se afina ao princípio da sustentabilidade por tratar independentemente de regulação legal, com eficácia direta e imediata, a responsabilidade do Estado e da sociedade pela concretização solidária do desenvolvimento material e imaterial, socialmente inclusivo, durável e equânime, ambientalmente limpo, inovador, ético e eficiente, no intuito de assegurar, preferencialmente de modo preventivo, no presente e no futuro, o direito ao bem-estar físico como o bem de todos (FREITAS, 2011).

Embora o conceito de desenvolvimento sustentável, segundo Silva (2013, p. 314), seja considerado "elástico" e esteja relacionado aos diferentes interesses no campo político e social, a defesa do meio ambiente deve estar conectada à defesa da

3 É importante ressaltar que o autor revê, no presente estudo, sua antiga definição de "refugiados ambientais" elaborada em 1993, na qual considerava apenas fatores ambientais como causas dos deslocamentos forçados. MYERS, Norman; KENT, Jennifer. Environmental Exodus: An Emergent Crisis in the Global Arena. Washington DC: Climate Institute, 1995. p. 18. 
justiça social, valorização do trabalho e à luta contra a mercantilização do mundo e à defesa da vida, não apenas como uma ideologia pronta e acabada que deve ser utilizada por países desenvolvidos ou organismos não governamentais.

\section{A SUPERAÇÃO DA PROBLEMÁTICA DA TUTELA JURÍDICA DO REFUGIADO AMBIENTAL NO BRASIL: 0 CASO HAITIANO}

As normas atuais sobre refugiados ambientais existentes são insuficientes na seara do Direito Internacional capacitados de proteger as vítimas de desastres ecológicos que são obrigadas a deixar seu local de origem em busca de condiçôes mínimas de vida, quando o seu país não é capaz de prover tais condições de subsistência.

A maioria dos migrantes, especialmente os migrantes forçados, encontra-se em situação irregular, uma vez que, ante a ausência de um sistema internacional de proteçáo, ficam a depender do esforço interno dos governos e da vontade política dos Estados de origem ou de destino, que muitas vezes são os principais responsáveis, direta ou indiretamente, pela violação e limitação de seus direitos fundamentais.

Embora a ONU e os países desenvolvidos prefiram não tratar da questão dos refugiados ambientais, trata-se de problema atual e urgente que não tem como ser ignorado, mostrando-se flagrante a necessidade de se buscar uma solução que harmonize o Direito Internacional vigente com a necessidade de proteção jurídica dos migrantes por causas ambientais.

Cabe ao Direito contribuir, no sentido de construir uma estrutura que ofereça proteção, mecanismos ou medidas que minimizem os efeitos dos deslocamentos e que possam garantir aos "refugiados" tratamento em conformidade com o princípio da dignidade da pessoa humana. Cumpre advertir que, isoladamente, políticas públicas, promulgaçáo de leis, criação de algumas normas ou um conjunto de conceitos, não soluciona o problema dos "refugiados ambientais"; estas medidas devem ser empregadas conjuntamente e fundadas nos valores e princípios que norteiam a sociedade (JESUS, 2009).

A proposição de alternativas e eventuais soluçôes, portanto, deve ser "alicerçada em técnicas como a ponderação ou harmonização de valores humanos". Por isso, uma análise sobre o reconhecimento jurídico da categoria "refugiados 
ambientais" também depende da forma como as questóes ambientais são tratadas pelas instituiçóes e pelos Estados, a qual explica, muitas vezes, a postura ativa ou a inércia destes diante da crise ambiental global e seus impactos sobre a mobilidade humana.

\subsection{Análise da Concessão do Visto Humanitário Concedido pelo Conselho Nacional de Refúgio}

No Brasil a Lei no 9.474/97, que dispóe sobre a concessão do status de refugiado, criou o Comitê Nacional para Refugiados (Conare), no âmbito do Ministério da Justiça, para a deliberação dos casos de refúgio. Uma vez tendo sido o indivíduo considerado refugiado, ele tem certos direitos e obrigaçóes garantidos pela legislação brasileira e pelos tratados internacionais dos quais o Brasil é signatário.

O caso dos refugiados haitianos que vieram para o Brasil após o terremoto de 12 de janeiro de 2010 é tipicamente de refugiados ambientais que se encontram no limbo jurídico pela falta de proteção específica, pois os haitianos que emigraram não são refugiados convencionais, mas são, sim, refugiados ambientais porque foram forçados a migrar em decorrência de um fator ambiental (neste caso, ocorrido sem a interferência antrópica no meio).

Por não serem refugiados amparados pela Convenção de 1951, esses haitianos não são passíveis de receberem proteçáo pela lei brasileira de refúgio, que ampliou o leque da Convençáo da ONU, mas que, como aquela, náo reconhece o distúrbio ambiental como base para a concessão de status de refugiado.

Observa-se que a residência permanente é comumente conferida aos estrangeiros com base na Lei no 6.815/1980 (Estatuto do Estrangeiro). Essa condição permite que o estrangeiro obtenha o Registro Nacional de Estrangeiros (RNE - que funciona como cédula de identidade do estrangeiro), CPF e Carteira de Trabalho e passe a obter subsistência por seus próprios meios, sendo, dessa forma, considerado um imigrante em situação regular no país.

No caso dos haitianos, a residência permanente foi concedida por meio da Resolução Normativa no 97, de 12 de janeiro de 2012, expedida pelo Conselho Nacional de Imigração (CNIG), que determina: 
Art. $1^{\circ}$ Ao nacional do Haiti poderá ser concedido o visto permanente previsto no art. 16 da Lei 6.815, de 19 de agosto de 1980, por razóes humanitárias, condicionado ao prazo de 5 (cinco) anos, nos termos do art.18 da mesma Lei, circunstância que constará da Cédula de Identidade do Estrangeiro.

Parágrafo único. Considera-se razóes humanitárias, para efeito desta Resolução Normativa, aquelas resultantes de agravamento de condiçóes devida da população haitiana em decorrência do terremoto ocorrido naquele país em 12 de janeiro de 2010.

Art. $2^{\circ} \mathrm{O}$ visto disciplinado por esta Resolução Normativa tem caráter especial e será concedido pelo Ministério das Relaçôes Exteriores, por intermédio da Embaixada do Brasil em Porto Príncipe.

Parágrafo único. Poderão ser concedidos até 1.200 (mil e duzentos) vistos por ano, correspondendo a uma média de 100 (cem) concessóes por mês, sem prejuízo das demais modalidades de vistos previstas nas disposições legais do País.

Nesse contexto, considerando a grave situação do Haiti, o Comitê Nacional para Refugiados (Conare), que recebeu seus pedidos de refúgio, decidiu buscar uma soluçáo alternativa e facilitar a permanência dos haitianos no Brasil. Por decisão conjunta entre governo e sociedade civil, decidiu-se remeter os processos ao Conselho Nacional de Imigração (CNIg) e ali, em novas e profundas reflexóes, foi tomada a decisão de conceder-lhes residência permanente por razóes humanitárias.

Essa espécie de visto humanitário, que na verdade se trata de visto permanente, foi criado para os haitianos pela Resolução Normativa no 97, de 12 de janeiro de 2012 pelo Conselho Nacional de Imigração (CNIg), concedendo um prazo de cinco anos de permanência no território brasileiro. A Resolução afere aos haitianos razóes humanitárias por se tratar de uma condição de reconhecimento internacional pela grave situação de destruição e despojamento de milhares de pessoas de suas residências em decorrência do terremoto que assolou o Haiti em 12 de janeiro de 2010. 
Observa-se que tal proteção decorre do Direito Humanitário consolidado como um marco de internacionalização dos direitos humanos, que nasceu da pretensão de proteger as pessoas que se encontravam em ambientes de conflitos armados ou em guerras, tendo como principal função instituir conjunto de normas para proteger esses indivíduos, bem como em tempo de paz se houver catástrofes naturais.

Outro papel importante do Direito Humanitário diz respeito a sua interação com a Organizaçáo Internacional do Trabalho, ambos com o intuito de promover a internacionalizaçáo dos direitos humanos, proporcionando meios para que os migrantes por motivos já explicitados anteriormente consigam se manter em outro território em condiçôes dignas de sobrevivência e com possibilidade de trabalhar para seu sustento.

Nessa perspectiva, o Brasil concedeu aos haitianos o visto permanente ao teor da lei que define a situação jurídica do estrangeiro, lei no 6.815 de 19 de agosto de 1980, e da Resoluçáo Normativa no 97/2012 do CNI, tendo como uma das condicionantes dessa espécie de visto a exigência de atividade laboral.

Como consequência do poder soberano sobre esta proteção, o solicitante de refúgio pode ficar sujeito a uma vida nua no Estado, sem direitos, uma vez que eles podem ser suspensos conforme os interesses nacionais, sem possibilidades de apelações, tendo em conta que "é o poder soberano que delimita quem está dentro e quem está fora, ou, de outra forma, quem deve ou não ser despido de direitos, isto é, nulificado" (REDIN, 2013, p.32).

Por isso, o objetivo do visto considerado humanitário é de regularizar a situação dos haitianos no Brasil, além de assegurar uma condição de trabalho e bem-estar, tendo em vista que no começo dessa epopeia realizada pelos haitianos, acabavam chegando ao território brasileiro e encontrando dificuldade em conseguir um visto para permanência no país.

Uma vez que o número de haitianos que entravam no Brasil em situação irregular era grande, o visto humanitário (visto permanente) possibilitou que eles pudessem obter as mesmas garantias individuais asseguradas pela Constituição da República de 1988. 
Assim sendo, depreende-se dessa situação uma indagação pertinente no que diz respeito à concessão de visto humanitário em vez de reconhecimento de status de refugiados para os imigrantes haitianos.

\subsection{A Concessão do Visto Humanitário Versus Status de Refúgio}

O visto humanitário ou visto permanente no Brasil advém do Estatuto do Estrangeiro, cuja lei 6.815/80, já citada anteriormente, ao teor do artigo 18, dispóe sobre as condições de concessão e exigências que devem ser cumpridas, como a de prazo máximo de 5 (cinco) anos de permanência no Brasil e exercício de atividade laboral certa em local fixo.

Já o status de refugiado atribui ao beneficiado com este instituto uma série de direitos provenientes do Estatuto do Refugiado - Lei no 9.474/97, além do amparo legal dos diplomas internacionais da Convenção sobre os Refugiados de 1951 e Protocolo de 1967.

Para obter o status de refugiado basta o indivíduo solicitar a qualquer autoridade migratória que ele encontre na fronteira, e até o trâmite final do processo de pedido de refúgio, o solicitante não poderá ser deportado - princípio do non-refoulement-e o ingresso mesmo ilegal náo constitui empecilho para solicitação de refúgio.

A principal diferença entre os dois institutos, contudo, é no tocante aos benefícios que cada um proporciona: o refugiado dispóe de uma série de direitos e garantias, direito à hospedagem, segurança, ajuda financeira provenientes de atuação da Acnur e do governo brasileiro; já o visto humanitário apenas dá a concessão ao estrangeiro de trabalhar, visando a sua sobrevivência no território nacional.

\section{CONSIDERAÇÕES FINAIS}

Ainda que não haja uniformidade sobre a expressão "refugiados ambientais", não se pode negar a existência de um problema a ser solucionado e, até o momento, sem resposta pelo Direito Internacional Público, seja sob a perspectiva do Direito Internacional dos Direitos Humanos, do Direito Internacional dos Refugiados ou mesmo pelo Direito Internacional do Meio Ambiente. 
Integrar todas essas perspectivas parece ser o caminho mais viável para uma solução eficaz do problema, que demanda um tratamento jurídico de âmbito global e o compromisso de toda a comunidade internacional nesse sentido.

Aparentemente essas perspectivas parecem não dialogar, pois de um lado está a perspectiva humanitária, de assistência aos deslocados e aos refugiados. De outro, as demais perspectivas: ambiental, econômica, política. Ambas, no entanto, estão relacionadas ao fenômeno das alteraçóes do ambiente global e não só podem, mas devem se comunicar. A inter-relação necessária entre as diversas perspectivas foi sempre ressaltada ao longo da presente pesquisa.

Observa-se que o conceito de refugiado não evoluiu para acompanhar a realidade atual do planeta, permanecendo estático e restrito apenas às vítimas de perseguiçôes políticas, étnicas e ideológicas, no entanto há uma nova categoria de migrantes, com características de refugiados, que estão sendo impelidos a deixarem os seus lares e muitas vezes o seu país de origem, em razão de catástrofes ambientais, e que não contam com qualquer amparo legal internacional.

Resta claro que há uma resistência dos Estados e organismos internacionais em relação ao reconhecimento do migrante ambiental como refugiado, estando entre os óbices apontados na doutrina para a consolidação de tal conceito a falta de suporte legal da Convenção de Genebra para o reconhecimento do refugiado ambiental, o risco de enfraquecimento do regime internacional de refugiados, o ônus econômico e social para os países receptores, as barreiras culturais e étnicas entre as vítimas e os Estados que irão acolhê-las.

Ressalta-se que o instituto do refúgio não está isolado no Direito Internacional e deve ser compreendido como instrumento de garantia do exercício pleno dos direitos humanos. A legislaçáo brasileira foi atualizada e ampliou a possibilidade de concessão de refúgio ao incluir na Lei 9.474/97 a condição de refugiado a todo aquele que "devido a grave e generalizada violação dos direitos humanos, é obrigado a deixar seu país de nacionalidade e buscar refúgio em outro país", contemplando os casos de tragédias ambientais ou naturais, principalmente se tais eventos são potencializados pelo caos social e político da regiáo, como é o caso específico do 
Haiti, que viveu esse caos durante décadas antes do grande terremoto de 2010, levando seus cidadãos exatamente à situação de vítimas de graves violaçôes dos direitos humanos.

Com esta atitude do Judiciário, não havia outra maneira senão uma intervenção do governo federal para tentar solucionar este problema. Foi entáo que o Conselho Nacional de Imigração publicou a Resolução 97, de janeiro de 2012, criando o visto humanitário para estes estrangeiros.

Assim, ao avaliar a concessão do visto humanitárias concedido aos haitianos, com base na Resolução Normativa n. 97/2012, o Estado brasileiro, por meio do CNIg, agiu de forma provisória e discricionária, ao interpretar de forma restrita a aplicação da concessão de refúgio disposto na Lei no 9.474/97, expondo os imigrantes ambientais à vulnerabilidade e à violação dos direitos humanos.

No contexto atual, portanto, não é admissível diante das evidências de que o meio ambiente se tornou um fator determinante para os fluxos migratórios (degradação ambiental como causa) e de que a migração pode causar um impacto direto e substancial no ambiente (alteração ambiental como consequência). A delimitação de uma categoria especial de migrantes, "refugiados ambientais", torna-se fundamental para a proteção internacional e dos Estados desses deslocados.

\section{REFERÊNCIAS}

BARROS, Miguel Daladier. O drama dos refugiados ambientais no mundo globalizado. Brasília: Consulex, 2011.

BRASIL. Lei n ${ }^{\circ} 9.474$ de 22 de julho de 1997. Define os mecanismos para a implementação do estatuto dos refugiados de 1951 e determina outras providências. Disponível em: <http:// www.planalto.gov.br/ccivil_03/Leis/L9474.htm>. Acesso em: 1ºut. 2016.

CONVENÇÃO RELATIVA AO ESTATUTO DOS REFUGIADOS. Disponível em: $<$ http://www.acnur.org/t3/fileadmin/scripts/doc.php?file=t3/fileadmin/Documentos/portugues/BDL/Convencao_relativa_ao_Estatuto_dos_Refugiados>. Acesso em: 22 out. 2016.

COURNIL, Christel; MAZZEGA, Pierre. Réflexions prospectives sur une protection juridique des réfugiés écologiques. In: Revue Européenne des Migrations Internationales, n. 1, 2007. 
DECLARAÇÃO DE CARTAGENA. Disponível em: <http://www.migrante.org.br/ refugiados_e_migracoesforcadas16jun05b.htm>. Acesso em: 10 out. 2016.

DOLINGER, Jacob. Direito Internacional Privado - parte geral. 8. ed. Rio de Janeiro: Renovar, 2005.

EL-HINNAWI, Essam. Environmental Refugees. Nairobi: United Nations Environment Programme - Unep, 1985.

FREITAS, Juares. Sustentabilidade: direito ao futuro. Belo Horizonte: Fórum. 2011.

INSTITUTO DE MIGRAÇÓES E DIREITOS HUMANOS - IMDH. Glossário. Disponível em: <www.migrante.org.br/IMDH/ControlConteudo.aspx?area=90211527-9d7f-4517-a34c-4ae25cdabac>. Acesso em: 24 out. 2016.

JESUS, Tiago Schneider de. Um novo desafio ao direito: deslocados/migrantes ambientais. Reconhecimento, proteção e solidariedade. 2009. 128f. Dissertação (Mestrado em Direito) - Faculdade de Direito, Universidade de Caxias do Sul, Caxias do Sul, 2009.

MYERS, Norman; KENT, Jennifer. Environmental Exodus: An Emergent Crisis in the Global Arena. Washington DC: Climate Institute, 1995.

PROGRAMA DAS NAÇÓES UNIDAS PARA O MEIO AMBIENTE (Pnuma). Disponível em: <http://www.onu.org.br/onu-no-brasil/pnuma/>. Acesso em: 24 out. 2016.

PROTOCOLO SOBRE O ESTATUTO DOS REFUGIADOS. Disponível em: <http:// www.acnur.org/t3/portugues/recursos/documentos/>. Acesso em: 2 out. 2016.

ORGANIZAÇÃO INTERNACIONAL PARA MIGRAÇÃO (OIM). Disponível em: $<$ https://www.iom.int/cms/en/sites/iom/home/about-migration/key-migration-terms-1. html\#refugees. Acesso em: 24 out. 2016.

REDIN, Giuliana. Direito de imigrar: direitos humanos e espaço público. Florianópolis: Conceito, 2013.

SILVA, M. B. O. da. Direito ao desenvolvimento e à sustentabilidade ambiental: diálogos e conflitos no balizamento jurídico do desenvolvimento (sustentável). In: TYBUSCH Jerônimo (Org.). Direitos emergentes na sociedade global: anuário do programa de pós-graduação em direito da UFSM. Ijuí: Ed. Unijuí, 2013.

TRINDADE, Antônio Augusto Cançado. Direitos humanos e meio ambiente: Paralelo dos sistemas de proteção internacional. Porto Alegre: Sérgio Antonio Fabris, 1993. 